\title{
Energy and exergy analysis of combined cooling and power system using variable mode adsorption chiller
}

\author{
Ahmad A. Alsarayreh ${ }^{1, *}$, Ayman Al-Maaitah ${ }^{2}$, Menwer Attarakih $^{3}$, and Hans-Jörg Bart ${ }^{4}$
}

\author{
${ }^{1}$ Precision Industries, P.O.Box: 37448, Dubai, United Arab Emirates \\ ${ }^{2}$ Wahaj Investment L.L.C., 24B St, Comm-365, Ind 2-Dubai, United Arab Emirates; ayman@ wahajsolar.com \\ ${ }^{3}$ Department of Chemical Engineering, University of Jordan, Queen Rania St, 11942 Amman, Jordan; attarakih67@ gmail.com \\ ${ }^{4}$ Thermische Verfahrenstechnik, TU Kaiserslautern, 67653 Kaiserslautern, Germany; bart@mv.uni-kl.de \\ *Correspondence: ahmadsarayrah@ymail.com; Tel.: +971-543061810
}

\begin{abstract}
Adsorption cooling is a promising technology to recover low-temperature waste heat from a diesel genset. In this paper, an advanced adsorption chiller working in variable mode is proposed for the combined cooling and power cycle (CCP) to recover waste heat from the water jacket in the diesel genset. The chiller works on three modes based on the ambient temperature for better heat utilization. In this study, three modes were investigated: single-stage cycle mode, short-duration, and medium-duration mass recovery modes. The results show that the energy and exergy efficiency for a single-stage cycle mode is higher at an ambient temperature lower than $35{ }^{\circ} \mathrm{C}$. In comparison, the mass recovery mode has a higher energy and exergy efficiency at an ambient temperature higher than $35^{\circ} \mathrm{C}$. The annual energy and exergy efficiency for the CCP was investigated when the chiller works with variable modes based on the ambient temperature under DUBAI weather conditions as a case study. The results show an improvement of $14.7 \%$ and $14 \%$ of the energy and exergy efficiency, respectively, for CCP with a variable mode adsorption chiller compared to diesel genset alone. The results also show the CCP with variable mode adsorption chiller has a slight improvement on both energy and exergy efficiency compared to CCP with a single-stage adsorption chiller at the same ambient conditions.
\end{abstract}

\section{Introduction}

Cooling application is one of the highest consumers of the primary energy in United Arab Emirate [1]. In most remote areas located in the desert where there is no grid power supply, such as safari camps, diesel gensets are typically used as a power source [2]. Such gensets have a relatively low thermal efficiency of about $35 \%$ [3]. While about $65 \%$ of the generated heat is rejected to the ambient as waste heat [4], $25 \%, 33 \%$, and $7 \%$ is wasted in the coolant, exhaust gas, and friction, respectively[5].

Depending on the temperature, heat is usually classified into three categories: high-grade $\left(649{ }^{\circ} \mathrm{C}\right.$ and higher), medium-grade $\left(232-649{ }^{\circ} \mathrm{C}\right)$, and low-grade (232 ${ }^{\circ} \mathrm{C}$ and lower) [6]. The rejected heat to the coolant (jacket water and aftercooler) is a low grade as shown in Figure 1, and can be recovered easily at a temperature range of $80-90{ }^{\circ} \mathrm{C}$.

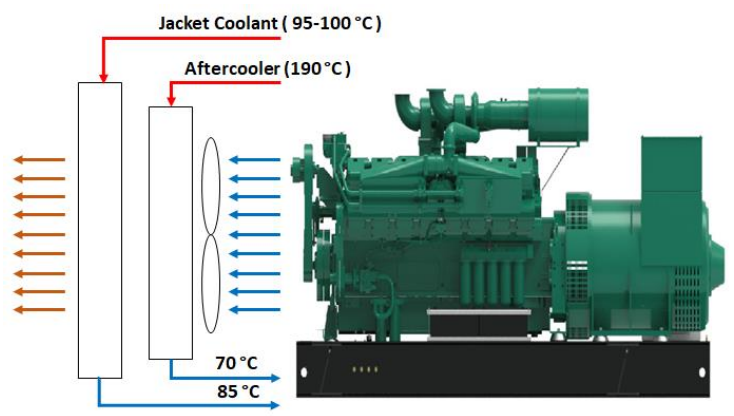

Fig. 1. Diesel genset cooling system
The cooling application is one of the highest energy consumers in UAE. This makes the combined coolingpower (CCP) an interesting option for energy saving and reducing Greenhouse Gases (GHG) emissions by utilizing waste heat at low-temperature levels from the diesel genset to drive thermal cooling technologies, as absorption and adsorption cooling.

Most studies investigate waste heat-driven absorption cooling technology. The absorption cooling system working principle is based on the refrigerant and absorbent (binary solution) [7]. The absorption chiller system consists of the absorber, pump, condenser, and genset. Two commonly refrigerant-absorbent pairs are used: lithium-bromide ( $\mathrm{LiBr})$ as a solvent and water, ammonia, and water as a refrigerant. LiBr-water is a very known pair and used commonly in most absorption chillers. This pair can work as a single effect cycle at a low driving temperature and a double effect cycle at a higher driving temperature [8].

A prototype of an ammonia-water absorption refrigeration system was investigated for a fishing prototype, driven by engine exhaust gas [9]. The result showed that the proposed prototype system could save from $2 \%$ to $4 \%$ of the total ship fuel consumption. Cogeneration of the electricity-cooling system was investigated by [10]. In this study, the water heat from a ship engine coolant and exhaust gases was used to drive a combined Rankine-absorption chiller (NH3/H2O). The study results showed that the exergy efficiency improved by $5-12 \%$ compared to the basic Rankine cycle only. An economical, energetic and environmental assessment

\footnotetext{
* Corresponding author: ahmadsarayrah@ymail.com
} 
study of combined production of electricity, heat, and cold in (Spain), the proposed system consisted of natural gas cogeneration engines to provide electricity, heating, and cooling by single-effect $\mathrm{H} 2 \mathrm{O} / \mathrm{LiBr}$ absorption chiller driven by directly cooling water from internal combustion cogeneration engines. The study results showed that the proposed system can reduce the primary energy consumption and $\mathrm{CO}_{2}$ emissions by up to $24 \%$ [11] .

Some researchers also investigated waste heat-driven adsorption chillers. The principle of adsorption works with the interaction of gases and solids. It involves physical uptake of the refrigerant (adsorbate) on the surface of the adsorbent, such as silica gel, zeolite, and activated carbon by van der Waal's or polar bonding forces [12]. The adsorption cooling system consists mainly of an evaporator, condenser, adsorbent chambers, hot and cold water circuits, and water pumps. The adsorption-cooling cycle consists of four main processes: isosteric heating, desorption, isosteric cooling, and adsorption [13]. An experimental study involving a waterzeolite adsorption cooling system for a truck cabin driven by waste heat from the vehicle engine, showed that the system could cover a significant amount of the cooling load [14]. [15] investigated the influence of using an adsorption chiller on a conventional CHP power plant. The study shows that only $10 \%$ to $15 \%$ of the total heat output from the CHP plant is required for heating purposes in the summer season. Using the adsorption system increases the plant's efficiency as $90 \%$ of the waste heat could be used for cooling.

Compared to absorption technology, the adsorption technology has advantages in the fewer moving parts and lower electrical consumption. But on the other hand, it has a lower COP [16]. The COP and cooling capacity for adsorption cooling are very sensitive with re-cooling and ambient temperature [17]. Researchers introduced some advanced adsorption cooling cycles to improve the adsorption cooling cycle performance, including a reheating cycle [18] and a mass recovery cycle [19]. The simple single-stage cycle has better performance at low re-cooling and ambient temperatures for air-cooled application, while the mass recovery cycle with heating and cooling has better performance at higher re-cooling and ambient temperatures [20].

It is clear from the previous literature that, using and recovering waste heat from power generation systems, diesel engines, and power plants improves the total system efficiency. However, one of the main challenges on the CCP system performance is the impact of varying ambient temperature. Optimizing the cooling system based on the ambient temperature will maximize the benefit of the waste heat, which is the main task of this study. This study aims to investigate the energy and exergy performance of a CCP system using a variablemode adsorption chiller under various ambient temperatures.

\section{Combined cooling and power system}

This study investigates a proposed Combined Cooling and Power System (CCP). The proposed system consists of a variable-mode adsorption chiller driven by waste heat from a diesel genset. The waste heat from the diesel genset coolant will be recovered by a plate heat exchanger to power the adsorption chiller. Both the adsorption chiller and diesel genset are connected with a remote sandwich radiator to minimize electrical energy consumption instead of having a separate dry cooler for the adsorption chiller and another radiator for the diesel genset. The remote radiator will be used to control the inlet coolant temperature to the genset to the recommended range, especially when the adsorption chiller is not working. It will also be used to dissipate the waste heat from the chiller to an ambient temperature range.

Figure 2 summarizes the proposed CCP concept, while Figure 3 shows the 3D model for the proposed system. Table 1 summarizes the selected technical data of the diesel genset.

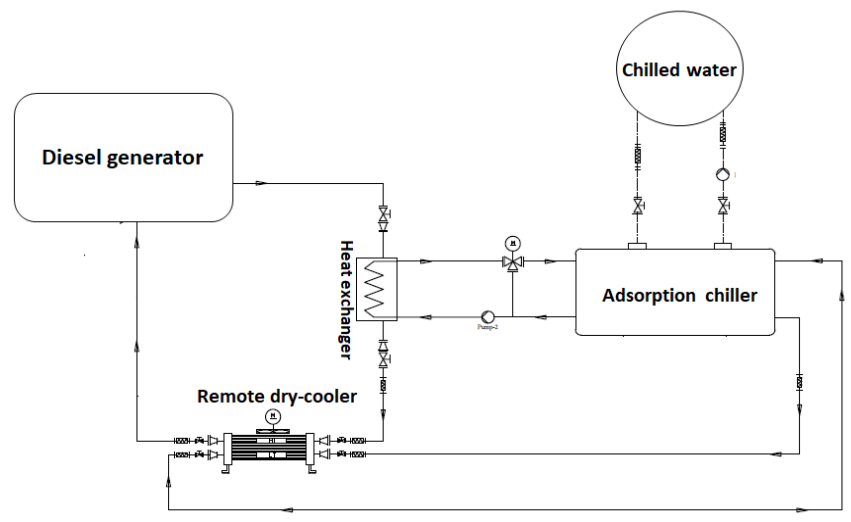

Fig. 2. Schematic diagram of the proposed CCP system

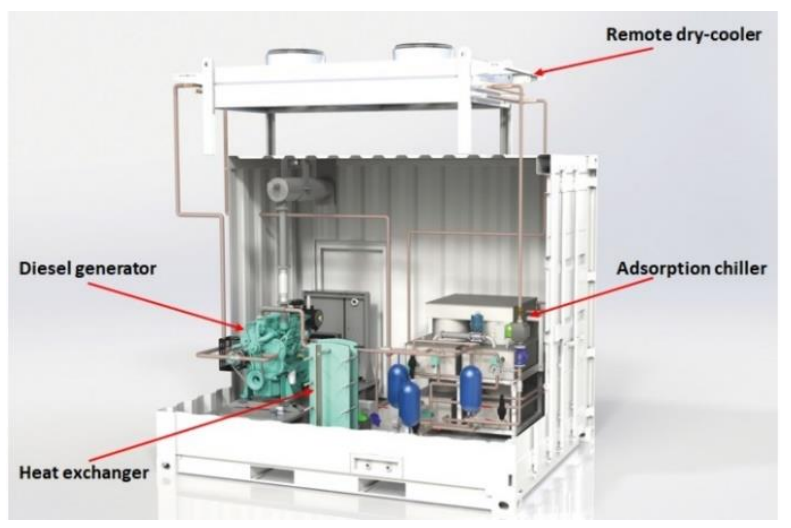

Fig. 3. 3D model of the proposed CCP system

The system is analyzed hourly based on the below assumptions in Table 1:

Table 1: Diesel engine's technical data

\begin{tabular}{|c|c|c|c|}
\hline \multirow{2}{*}{ Application } & $\%$ & $\begin{array}{c}\text { Power } \\
\text { output } \\
(\mathrm{KW})\end{array}$ & $\begin{array}{c}\text { Fuel Con- } \\
\text { sumption } \\
\text { (L/h) }\end{array}$ \\
\hline \multirow{3}{*}{ Standby power } & 100 & 102 & 27 \\
\hline & 100 & 93 & 25 \\
\cline { 2 - 4 } & 75 & 70 & 18 \\
\cline { 2 - 4 } & 50 & 47 & 12 \\
\cline { 2 - 4 } & 25 & 23 & 7 \\
\hline \multicolumn{3}{|c|}{ Model: 6BTA5.9-G5 /Manufacturer: Cummins } \\
\hline
\end{tabular}




\section{Variable mode adsorption chiller}

The proposed adsorption chiller in this study works with variable modes based on the ambient condition. The chiller works at the single-stage mode at low ambient temperatures and with the two mass recovery cycle modes at high ambient temperatures. The chiller consists of two adsorbent beds, a condenser, an expansion valve, an evaporator, four non-return valves, and a motorized ball valve, as shown in Figure 4. The adsorbent beds work as an adsorber and a desorber. The motorized valve opens once the adsorption/desorption process ends, which allows the high-pressure hot refrigerant to flow from the desorber to the adsorber, which is called mass recovery with heating and cooling. Changes in the mass recovery duration is dependent on the ambient temperature. This concept is filed for a patent by Precision Industries (www.PI-Dubai.com). Figures 5 and 6 show the proposed adsorption chiller cooling capacity and COP based on modeling and experimental results conducted at Precision Industries lab. Figures 5 and 6 show that there are three modes: single-stage, short mass recovery mode with heating and cooling (where the mass recovery duration equals to $25 \%$ of the cooling cycle), and the medium mass recovery mode with heating and cooling (where the mass recovery duration equals to $50 \%$ of the cooling cycle duration).

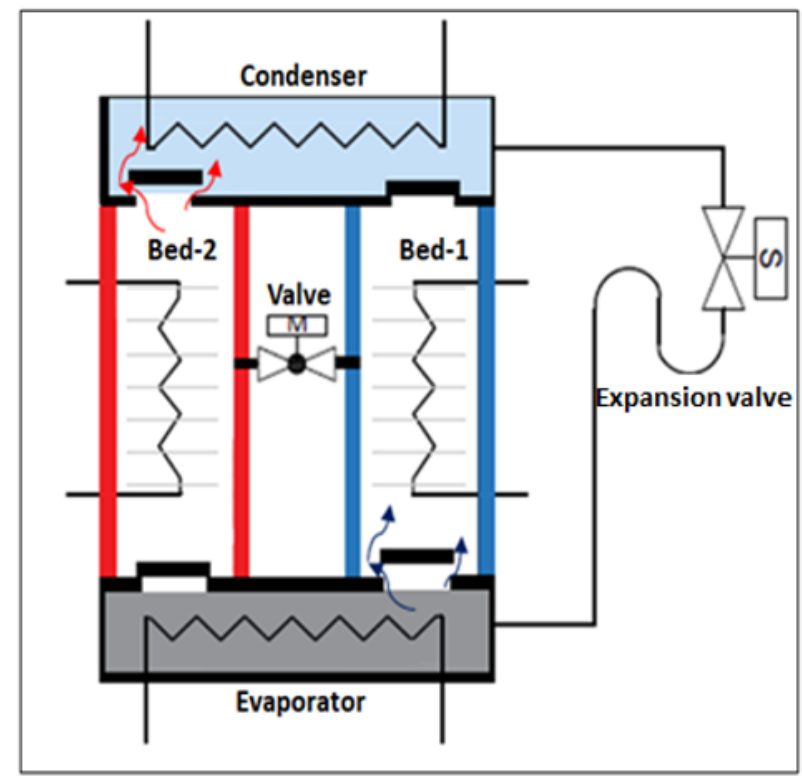

Fig. 4. Schematic diagram of the adsorption-cooling system

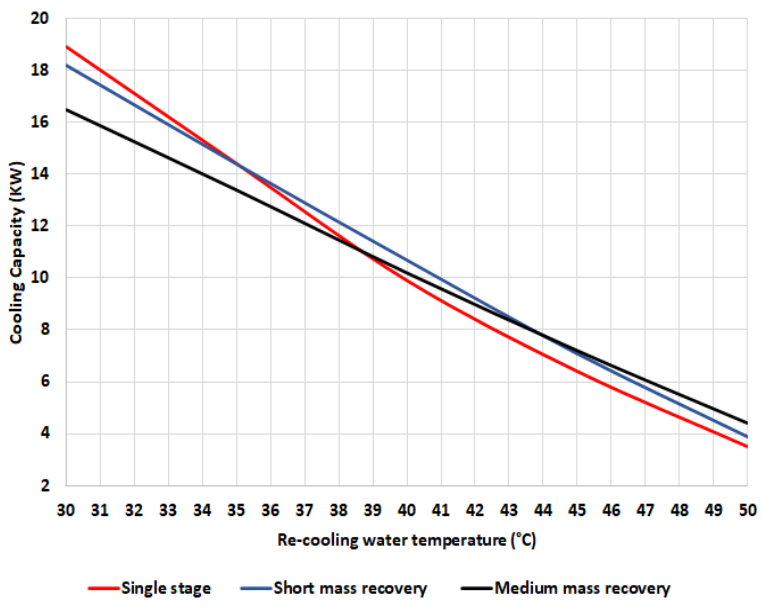

Fig. 5. Proposed adsorption chiller cooling capacity at various modes and ambient temperatures at $90{ }^{\circ} \mathrm{C}$ hot water inlet and $18{ }^{\circ} \mathrm{C}$ chilled water inlet

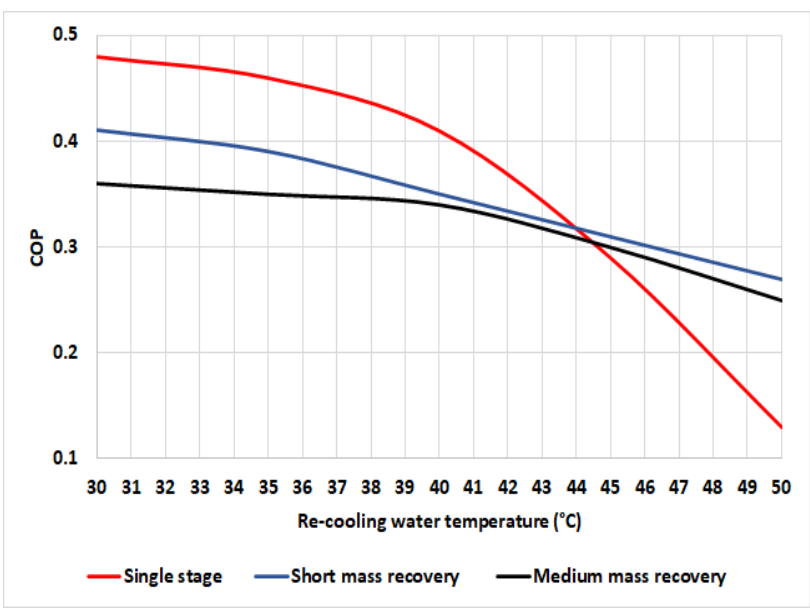

Fig. 6. Proposed adsorption chiller $\mathrm{COP}$ at various modes and ambient temperatures at $90^{\circ} \mathrm{C}$ hot water inlet and $18{ }^{\circ} \mathrm{C}$ chilled water inlet

\section{Mathematical model}

The total system efficiency ( $\eta_{\text {energy }}$ ) of a CCP system includes both the net useful electric output $P_{n e t}$ and the net useful thermal output, which is the cooling output $Q_{\text {eva }}$ divided by the total fuel energy input $\left(Q_{f}\right)$, as shown in Equations 1 and 2 [21]:

$$
\begin{aligned}
& \eta_{\text {energy }}=\frac{P_{\text {net }}+Q_{\text {eva }}}{Q_{f}} \\
& P_{\text {net }}=P_{\text {Genset }}-P_{\text {Ads }}
\end{aligned}
$$

With:

$\eta_{\text {energy }}$ CCP thermal energy efficiency
$P_{\text {net }} \quad$ useful electric output from the genset
$P_{\text {Genset }}$ total electric output from the genset
$P_{\text {Ads. }}$ electric power consumed in the adsorption chiller
$Q_{\text {eva }} \quad$ chiller cooling capacity (evaporator output)
$P_{\text {net }} \quad$ useful electric output from the genset


$Q_{f} \quad$ fuel energy input

The fuel energy input can be calculated as shown in Equation 3 [22] :

$Q_{f}=m_{f} \times L H V_{f}$

Where:

$m_{f} \quad$ mass flow of the fuel

$L H V_{f}$ the lower heating value of the fuel

The exergy efficiency $\left(\eta_{\text {exergy }}\right)$ is measured as the ratio of exergy input to the output in the system as useful output [23]. It can be calculated as per Equation 4:

$\eta_{\text {exergy }}=\frac{P_{n e t}+E_{Q c h}}{E_{Q f}}$

Where:

$\eta_{\text {exergy }} \mathrm{CCP}$ exergy efficiency

$P_{\text {net }} \quad$ useful electric output from the genset

$E_{Q c h} \quad$ exergy of evaporator

$P_{\text {net }} \quad$ useful electric output from the genset

$E_{Q f} \quad$ exergy of fuel input

The exergy of the evaporator can be calculated as per Equation 5 [21]:

$E_{Q c h}=Q_{c h}\left(1-\frac{T_{0}}{T_{e v a}}\right)$

Where:

$T_{0} \quad$ dead state reference temperature

$T_{\text {eva }}$ evaporator temperature

\section{CCP analysis results and discussion}

The energy and exergy efficiency of CCP with adsorption chiller was analyzed on an hourly basis based on DUBAI weather conditions obtained from a Typical Meteorological Year (TMY). The analysis was done using Microsoft Excel and conducted for four scenarios for the chiller operation: single-stage cycle mode, short-duration, and medium-duration mass recovery modes, and variable mode (where the chiller works on the maximum cooling capacity depend on the ambient temperature).

The analysis was done under the following assumptions:

- The diesel genset works continuously on a prime rating of $75 \%$.

- The chiller works at an ambient temperature range of $30{ }^{\circ} \mathrm{C}-45^{\circ} \mathrm{C}$

- There is a continuous cooling demand.

- The hot water inlet temperature is $90^{\circ} \mathrm{C}$.

- The chilled water inlet temperature is $18^{\circ} \mathrm{C}$.

Figure 7 shows that the exergy efficiency decreases with increasing ambient temperatures because the increase in ambient temperature is associated with increasing re-cooling-water temperature. The COP and cooling capacity decreases with an increase in the recooling-water temperature. Figure 7 also shows that the energy efficiency for a single mode is higher at ambient temperatures lower than $35^{\circ} \mathrm{C}$. In comparison, the mass recovery modes have a higher energy and exergy efficiency at ambient temperatures higher than $35^{\circ} \mathrm{C}$.

It can be noted from Figure 8 that the exergy efficiency gradually increases to a maximum value and then decreases rapidly. It can also be noted that the exergy efficiency is maximized at a specific ambient temperature for each operation mode.

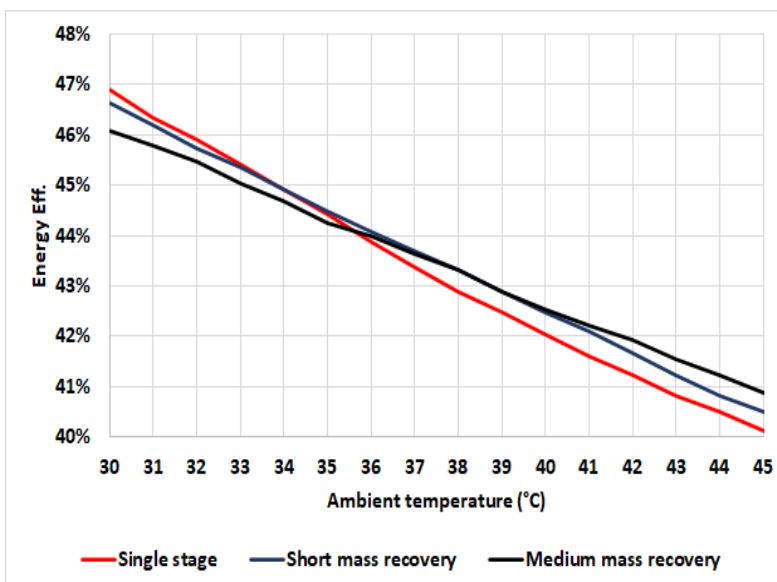

Fig. 7. CCP energy efficiency at various ambient temperatures

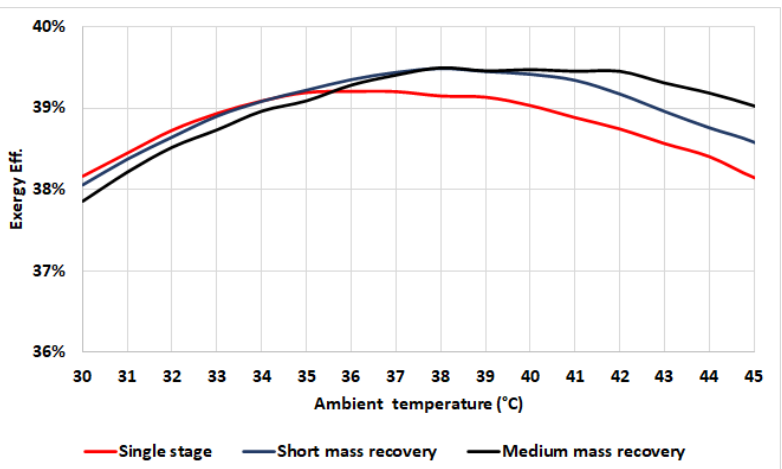

Fig. 8. Exergy efficiency at various ambient temperatures

In practice, the ambient temperature profile should be taken into consideration while assessing the energy and exergy efficiency. An estimation analysis is done on an annual basis under Dubai weather conditions for singlestage mode and variable mode adsorption cooling cycle. In the variable mode, the chiller works on a single-stage or mass recovery mode based on the ambient temperature. The analysis results in Table 2 show a significant improvement in the total energy and exergy efficiency for the CCP compared to the diesel genset; the improvement in energy and exergy efficiency is $14.7 \%$ and $14 \%$, respectively. The analysis results also show that the CCP with variable mode shows a slight improvement in both energy and exergy efficiency compared to CCP with a single-stage adsorption chiller, as shown in Table 2.

Table 2: The annual energy and exergy efficiency

\begin{tabular}{|c|r|r|l|}
\hline Cycle & $\begin{array}{l}\text { Diesel } \\
\text { engine }\end{array}$ & $\begin{array}{l}\text { CCP with } \\
\text { variable } \\
\text { mode chiller }\end{array}$ & $\begin{array}{l}\text { CCP with } \\
\text { single stage } \\
\text { mode chiller }\end{array}$ \\
\hline Energy eff. & $38.6 \%$ & $44.3 \%$ & $43.6 \%$ \\
\hline Exergy eff. & $34.6 \%$ & $39.4 \%$ & $38.8 \%$ \\
\hline
\end{tabular}




\section{Conclusions}

This study investigated a CCP system with an adsorption chiller for four operation scenarios for the proposed chiller; single-stage mode, short mass recovery mode, medium mass recovery mode, and variable mode. The results show that energy and exergy efficiencies for single-mode are higher at ambient temperatures lower than $35^{\circ} \mathrm{C}$. The mass recovery modes have a higher energy and exergy efficiency at ambient temperatures higher than $35^{\circ} \mathrm{C}$. Exergy efficiency analysis shows that the exergy efficiency is maximized at a specific ambient temperature for each operation mode.

The annual energy and exergy analysis under DUBAI weather conditions shows a significant improvement in the total energy and exergy efficiency for the CCP compared to only the Diesel engine. Also the results of analysis show that the CCP with variable mode shows an improvement in both energy and exergy efficiency, compared to CCP with a single-stage adsorption chiller.

\section{References}

1. G. Rohani and M. Nour, Energy 64, 828-841 (2014). 2. Z. M. Omer, A. A. Fardoun and A. M. Alameri, Energy Procedia 75, 3027-3035 (2015).

3. S. N. Hossain and S. Bari, Energy Convers. Manage. 75, 141-151 (2013).

4. D. Baidya, M. A. R. de Brito, A. P. Sasmito, M. Scoble and S. A. Ghoreishi-Madiseh, J. Cleaner Prod. 225, 785-805 (2019).

5. S. Bari, An Experimental Study of a Waste Heat Recovery System Connected to a Diesel-Gen-Set, Vol. SAE International, (2017).

6. I. Johnson, W. T. Choate and A. Davidson, Waste Heat Recovery. Technology and Opportunities in U.S. Industry, BCS Inc., Washington, D.C., (2008).

7. P. Srikhirin, S. Aphornratana and S. Chungpaibulpatana, Renewable Sustainable Energy Rev. 5 (4), 343-372 (2001).

8. T. Nunez, Journal of Sustainable Energy 1 (2010).
9. J. Fernández-Seara, A. Vales and M. Vázquez, Appl. Therm. Eng. 18 (12), 1189-1205 (1998).

10. Y. Liang, G. Shu, H. Tian, X. Liang, H. Wei and L. Liu, Energy Convers. Manage. 76, 1053-1060 (2013).

11. J. Ortiga, J. C. Bruno and A. Coronas, Appl. Therm. Eng. 50 (2), 1536-1542 (2013).

12. K. Thu, Adsorption desalination: theory \& experiments, Ph.D. Thesis, National University of Singapore, (2010).

13. H. Ambarita and H. Kawai, Case Stud. Therm. Eng. 7, 36-46 (2016).

14. M. Verde, L. Cortés, J. M. Corberán, A. Sapienza, S. Vasta and G. Restuccia, Appl. Therm. Eng. 30 (13), 1511-1522 (2010).

15. K. Sztekler, W. Kalawa, S. Stefański, J. Krzywanski, K. Grabowska, M. Sosnowski and W. Nowak, MATEC Web of Conferences 240, 05033 (2018).

16. J. White, Latin American and Caribbean Journal of Engineering Education (378-884-1-RV) (2013) (2013).

17. N. G. Ghilen, Slimane; Benelmir, Riad; Ganaoui, Mohammed El, J. Fundam. Renew. Energy Appl.7 (3) (2017).

18. K. C. A. Alam, M. Khan, A. Uyun, Y. Hamamoto, A. Akisawa and T. Kashiwagi, Appl. Therm. Eng. 27, 1686-1692 (2007)

19. A. Akahira, K. C. A. Alam, Y. Hamamoto, A. Akisawa and T. Kashiwagi, Int. J. Refrig. 28, 565-572 (2005)

20. A. A. Alsarayreh, A. Al-Maaitah, M. Attarakih and H.-J. Bart, Energies 14 (8), 2172 (2021).

21. M. Puig-Arnavat, J. C. Bruno and A. Coronas, Appl. Energy 114, 845-856 (2014).

22. M. J. Moran, H. N. Shapiro, D. D. Boettner and M. B. Bailey, Fundamentals of Engineering Thermodynamics, 8th Edition. (Wiley, 2014).

23. J. Szargut, D. Morris and F. Steward, Exergy analysis of thermal, chemical, and metallurgical processes. (Hemisphere Publishing Corporation, New York ,1988). 